\title{
Higher serum 25-hydroxyvitamin D concentrations are associated with active pulmonary tuberculosis in hospitalised HIV infected patients in a low income tropical setting: a cross sectional study
}

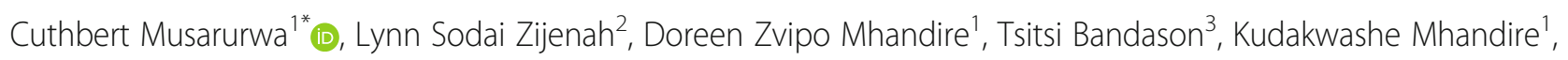
Maria Mary Chipiti ${ }^{2}$, Marshall Wesley Munjoma ${ }^{4}$ and Witmore Bayayi Mujaji ${ }^{1}$

\begin{abstract}
Background: The inherent risk of developing tuberculosis (TB) in HIV- infected individuals is further enhanced by hypovitaminosis D. Interventions that offset HIV-associated immune deterioration potentially arrest disease progression and incidence of opportunistic infections including TB. Despite conflicting reports on association between vitamin D deficiency (VDD) and risk of TB, vitamin D (VD) supplementation remains a promising intervention.

Methods: We conducted a comparative cross-sectional study on $145 \mathrm{HIV}^{+} /$pulmonary $\mathrm{TB}^{+}$(PTB) and $139 \mathrm{HIV}^{+} / \mathrm{PTB}^{-}$ hospitalised patients to investigate association of vitamin D status and risk of PTB. Stratified random sampling was used to select archived serum specimens from participants enrolled in a randomised controlled trial (RCT) conducted to investigate the impact of using a point-of-care urine lipoarabinomannan strip test for TB diagnosis. PTB status was confirmed using sputum smear microscopy, culture or GeneXpert MTB/RIF. Serum 25-hydroxyvitamin D [25(OH) D] concentrations were assayed by competitive chemiluminescent immunoassay prior to commencement of anti-TB treatment. Effect of VD status on duration of hospital stay and patient outcomes on follow up at 8 weeks were also investigated. Median serum 25(OH) D concentrations were compared using Mann-Whitney test and covariates of serum VD status were assessed using logistic regression analysis.

Results: Overall VDD prevalence in the cohort was 40.9\% (95\% Cl: 35.1-46.8). Median serum 25(OH)D concentrations were significantly higher in $\mathrm{HIV}^{+} / \mathrm{PTB}^{+}$group $\left(25.3 \mathrm{ng} / \mathrm{ml}\right.$, IQR:18.0-33.7) compared to the HIV+/PTB ${ }^{-}$group $(20.4 \mathrm{ng} / \mathrm{ml}$, IQR:14.6-26.9), $p=0.0003$. Patients with serum $25(\mathrm{OH}) \mathrm{D}$ concentration $\geq 30 \mathrm{ng} / \mathrm{ml}$ were 1.9 times more likely to be $\mathrm{PTB}^{+}$compared to those with serum 25(OH) D concentrations $<30 \mathrm{ng} / \mathrm{ml}$ (odds ratio (OR) 1.91; 95\% Cl 1.1-3.2). PTB-related death was associated with higher odds of having $25(\mathrm{OH}) \mathrm{D}$ levels $\geq 30 \mathrm{ng} / \mathrm{ml}$. Age, gender, CD4 ${ }^{+}$ count, combination antiretroviral therapy (CART) status, efavirenz based CART regimen and length of hospital stay were not associated with vitamin D status.

Conclusions: The finding of an association between higher serum 25(OH) D concentrations and active PTB and TB-related mortality among hospitalised HIV-infected patients in the present study is at variance with the commonly reported association of hypovitaminosis and susceptibility to TB. Our findings though, are in concordance with a small pool of reports from other settings.
\end{abstract}

Keywords: Vitamin D deficiency, Pulmonary tuberculosis, HIV, Hospital stay, cART

\footnotetext{
* Correspondence: curtbertm@yahoo.com

'Department of Chemical Pathology, University of Zimbabwe, College of

Health Sciences, P.O. Box A178, Avondale, Harare, Zimbabwe

Full list of author information is available at the end of the article
}

(c) The Author(s). 2018 Open Access This article is distributed under the terms of the Creative Commons Attribution 4.0 International License (http://creativecommons.org/licenses/by/4.0/), which permits unrestricted use, distribution, and reproduction in any medium, provided you give appropriate credit to the original author(s) and the source, provide a link to the Creative Commons license, and indicate if changes were made. The Creative Commons Public Domain Dedication waiver (http://creativecommons.org/publicdomain/zero/1.0/) applies to the data made available in this article, unless otherwise stated. 


\section{Background}

Zimbabwe, ranked 13th of 22 high TB burden countries that account for $80 \%$ of global TB burden has an HIV co-infection rate of approximately $68 \%$ [1]. In a lifetime, $10 \%$ of immunocompetent individuals asymptomatically infected with Mycobacterial tuberculosis (MTB), progress to active TB compared to $10 \%$ per year of HIVinfected individuals [2].

In vitro studies suggest vitamin D supplementation minimises progression to active TB given the role of vitamin $\mathrm{D}$ in immune regulation $[3,4]$. These studies reported further an association between hypovitaminosis D with decreased macrophage activation and suboptimal production of cathelicidin both of which blunt the host's ability to fight $\mathrm{TB}$ and other infections. One billion people worldwide are estimated to be vitamin D deficient [5]. HIV- infected individuals face a higher risk of hypovitaminosis $\mathrm{D}$ due to a unique risk profile associated with treatment or mere infection itself thus further enhancing susceptibility to TB [6]. HIV infection itself has been shown to increase metabolism of $25(\mathrm{OH}) \mathrm{D}$ into the active form, further driving vitamin D deficiency, due to gp120 induced CYP27B1 production [7].

Although some studies have associated VDD with poorer HIV infection outcomes and disease progression, in both cART-naive and treated patients $[8,9]$, the evidence for the association between VDD and increased TB risk is not sufficiently robust [10-12]. Clinical trials using $25(\mathrm{OH}) \mathrm{D}$ supplementation as adjunctive TB therapy reported no clinical benefits [13, 14] casting further doubt on the implied role of vitamin D on antimicrobial immunity. A study from The Gambia reported significantly higher median serum $25(\mathrm{OH}) \mathrm{D}$ concentrations in TB cases compared to tuberculin skin test positive controls and household contacts [10]. Another study conducted in Tanzania reported higher mean serum vitamin D levels in PTB patients compared to healthy controls but no significant difference between confirmed $\mathrm{PTB}^{+}$patients and $\mathrm{PTB}$ suspects who tested negative for PTB [15]. Both high and low serum vitamin D concentrations were associated with susceptibility to PTB in Greenlanders [16]. Furthermore, a meta-analysis concluded that the association between VDD and increased risk of TB was lacking in HIV-infected or - uninfected African populations [12].These conflicting findings may be attributed to underlying genetic differences, diet, exposure to sun or skin colour.

There is paucity of research on the relationship between vitamin D status and HIV-related outcomes, particularly in resource-limited settings where both HIV and TB are co-endemic. Interventions that offset immune deterioration associated with HIV infection can potentially arrest disease progression and incidence of opportunistic infections including TB. We examined the prevalence, covariates of VDD and risk of PTB among HIV- infected hospitalized patients with and without PTB.

\section{Methods}

\section{Study setting and design}

The study was conducted at Mabvuku Polyclinic and Parirenyatwa Group of Hospitals, Harare, Zimbabwe. Harare is located at an altitude of $1480 \mathrm{~m}$, latitude $17^{\circ}$ $55^{\prime} \mathrm{S}$ and longitude $31^{\circ} 7^{\prime} \mathrm{E}$. The mean daily sunshine duration is about $8.2 \mathrm{~h}$ with the rainy season stretching from November to April. Study participants were enrolled from January 2013 to September 2014.

Two hundred and eighty four hospitalised, Black Zimbabwean patients comprising $145 \mathrm{HIV}$ infected patients with active $\mathrm{PTB}\left(\mathrm{HIV}^{+} / \mathrm{PTB}^{+}\right)$and $139 \mathrm{HIV}$ infected patients without active $\mathrm{PTB}\left(\mathrm{HIV}^{+} / \mathrm{PTB}^{-}\right)$were randomly selected from a cohort $(n=920)$ who participated in a randomised controlled trial (RCT) entitled 'A RCT to evaluate the impact of using a point-of-care urine lipoarabinomannan (LAM) strip test for TB diagnosis amongst hospitalized HIV-infected patients in resource-poor settings (RCT LAM)' whose details are described elsewhere $[17,18]$. Briefly, to be eligible for inclusion into the RCT, potential participants were required to be HIV infected, presenting with any one of TB symptoms (fever, cough, drenching night sweats or self-reported weight loss) and sufficiently ill to warrant hospitalization. Patients demographic, clinical and laboratory data were abstracted from the RCT LAM database. Such data included length of hospital stay, and mortality outcomes 8-weeks post enrolment. Cause of death was recorded as tuberculosis, or not tuberculosis with the alternative cause of death specified. All data and specimens were anonymized before access was allowed to the current investigators.

\section{Study patients}

Consenting study patients aged $\geq 18$ years were all dark skinned, unveiled, with faces and arms regularly exposed to the sun. All were indigenous Zimbabweans, HIV- infected and suspected of having TB. Participants from the RCT-LAM study were stratified by PTB status before stratified randomisation was used to select participants from the RCT-LAM study. Participants who had been immobilised by illness for more than 2 weeks were excluded as were those with liver or renal conditions. Individuals who had already commenced anti-TB treatment and those on vitamin supplements were also excluded. The estimated sample size was 138 participants for each of the PTB status strata.

\section{Laboratory tests}

Blood specimens were collected for enumeration of CD4 + T-lymphocytes, haemoglobin and plasma and serum processing within $6 \mathrm{~h}$ of venepuncture before participants commenced anti-TB treatment.

At enrolment, each patient submitted at least three sputum specimens utilised as follows (i) same day PTB 
testing (Xpert Mycobacterium tuberculosis/rifampicin (MTB/RIF) Version G4 and fluorescence smear microscopy) (ii) TB culture and (iii) archived for future studies. Sputum smear fluorescence microscopy, Xpert MTB/RIF assay and the Mycobacteria Growth Indicator Tube (MGIT BD Microbiology Systems, Cockeysville, MD, USA) culture to confirm PTB, were performed as previously described $[17,18]$.

\section{5(OH) D assays}

Serum specimens archived at $-80{ }^{\circ} \mathrm{C}$ were retrieved and thawed only once before $25(\mathrm{OH}) \mathrm{D}$ assays were carried out. Serum 25(OH) D was measured as a marker of vitamin D status using a fully automated competitive chemiluminescent immunoassay analyser (Maglumi 2000 Snibe Co. Ltd. Shenzhen, 518,057 China) following manufacturer's instructions. Between-run precision coefficients of variation for the assay ranged from 6.04 to 6 . $25 \%$ and within run precision coefficients of variation ranged from $3.01-3.45 \%$.

Serum 25(OH) D concentrations reflect overall VD status because of a longer half-life of approximately 15 days compared to $15 \mathrm{~h}$ for the active form [19]. VDD was defined as serum $25(\mathrm{OH}) \mathrm{D}$ concentration $<20 \mathrm{ng} /$ $\mathrm{mL}$, vitamin D insufficiency as serum 25(OH) D concentration of $20-29 \mathrm{ng} / \mathrm{mL}$, and sufficient vitamin D status as serum $25(\mathrm{OH}) \mathrm{D} \geq 30 \mathrm{ng} / \mathrm{ml}$ [20]. Finally, 25(OH) D concentrations below $10 \mathrm{ng} / \mathrm{ml}$ were classified as severe VDD [21]. From these definitions, we further generated other dichotomies of vitamin $\mathrm{D}$ status as follows, optimal or suboptimal ( $\geq 30 \mathrm{ng} / \mathrm{ml}$ or $<30 \mathrm{ng} / \mathrm{ml}$ ) and deficient or not deficient $(<20 \mathrm{ng} / \mathrm{ml}$ or $\geq 20 \mathrm{ng} / \mathrm{ml})$.

\section{Ethics statement}

The study protocol was approved by the Medical Research Council of Zimbabwe (MRCZ/A/1906). All the patients in the parent study (RCT-LAM) consented to future use of their left-over archived specimens and data in future TB- and/or HIV-related studies.

\section{Statistical analyses}

Statistical analyses were conducted using STATA (version 13.0; Stata Corporation, College Station, Texas, USA). Counts and proportions (\%) were used to summarise data. Medians and interquartile range (IQR) were used to summarise non-normally distributed variables and means \pm standard deviations (SD) for normally distributed data. Differences in proportions were tested using the Chi-square test whilst differences between groups of continuous normally distributed data were tested using independent samples t-test and Mann-Whitney test for non-normal data. The prevalence of VDD was estimated in the whole sample and for the sub-groups $\left(\mathrm{PTB}^{-}\right.$and $\left.\mathrm{PTB}^{+}\right)$with $95 \%$ confidence intervals $(95 \% \mathrm{CI})$. Logistic regression was used to identify factors associated with VDD with OR and 95\% CI were reported for all such cases. For all statistical comparisons $\alpha$ was set at 0.05 .

\section{Results}

Baseline clinico-demographic characteristics of the patients are presented in Table 1.

Of the 284 patients, $142(50 \%)$ were female with median age 38 (IQR32-46) years. There was however no significant difference in gender $(p=0.893)$, age $(p=0.534)$ and duration of cART $(p=0.076)$ between $\mathrm{HIV}^{+} / \mathrm{PTB}^{+}$and $\mathrm{HIV}^{+} / \mathrm{PTB}^{-}$groups. Of 140 patients on cART, 109(77.9\%) were on an efavirenz (EFV)-based cART regimen.

There was however, no significant difference in proportions of patients on EFV-based regimen between the two groups $(p=0.061)$. At 8 -week follow-up, there was no significant difference in mortality rates $(p=0.057)$ between the two groups although the $\mathrm{HIV}^{+} / \mathrm{PTB}^{-}$patients stayed significantly longer in hospital compared to the $\mathrm{HIV}^{+} / \mathrm{PTB}^{+}(p<0.001)$. Median CD4+ T- lymphocyte counts were significantly lower in $\mathrm{HIV}^{+} / \mathrm{PTB}^{+}$patients $(p<0.001)$ as was mean haemoglobin concentration $(p$ $=0.03)$.

The median serum $25(\mathrm{OH})$ D concentrations and vitamin D status for all participant groups are presented in Table 2.

Overall median serum $25(\mathrm{OH}) \mathrm{D}$ concentration was 22 . $1 \mathrm{ng} / \mathrm{ml}$ (IQR16.4-31.5). The $\mathrm{HIV}^{+} / \mathrm{PTB}^{+}$group had significantly higher median serum $25(\mathrm{OH}) \mathrm{D}$ concentration $25.3 \mathrm{ng} / \mathrm{ml}$ (IQR18.0-33.7) compared to the $\mathrm{HIV}^{+} / \mathrm{PTB}^{-}$ group 20.4 (IQR14.6-26.9) $(p<0.0003)$. However the medians of each group and overall median of the two groups were all within the vitamin $\mathrm{D}$ insufficient range.

Distribution of serum 25(OH) D concentrations by PTB status is further illustrated in Fig. 1.

An overall 40.9\% (95\% CI: 35.1-46.8) were vitamin D deficient, 31\% (95\% CI: 25.7-36.62) were vitamin D insufficient and 28.2\% (95\% CI: 23.0-33.8) had sufficient concentrations. Only 1.8\% (95\% CI: 0.6-4.1) had severe VDD and all were $\mathrm{HIV}^{+} / \mathrm{PTB}^{-}$. Prevalence of VDD at $33.8 \%$ (95\% CI:26.2-42.1) was significantly lower in the $\mathrm{HIV}^{+} /$ $\mathrm{PTB}^{+}$compared to $\mathrm{HIV}^{+} / \mathrm{PTB}^{-}$group $(p=0.014)$. The $\mathrm{HIV}^{+} / \mathrm{PTB}^{-}$group had a significantly lower proportion of patients with optimal $25(\mathrm{OH}) \mathrm{D}$ concentration compared to $\mathrm{HIV}^{+} / \mathrm{PTB}^{+}$group $(p=0.016)$.

\section{Correlates of serum $25(\mathrm{OH}) \mathrm{D}$ levels}

The Wilcoxon rank-sum test was used to compare median $25(\mathrm{OH}) \mathrm{D}$ concentrations by age, gender, CD4+ Tlymphocyte count, body mass index (BMI), efavirenz (EFV) based cART regimen and cART status. Univariate and multivariate logistic regression analysis were also conducted to ascertain the influence of the same variables on serum vitamin D status (Table 3). For logistic 
Table 1 Participants clinico-demographic data

\begin{tabular}{|c|c|c|c|c|}
\hline Variable & All $n=284$ & $\mathrm{HIV}^{+} / \mathrm{PTB}^{+} n=145$ & $\mathrm{HIV}^{+} / \mathrm{PTB}^{-} n=139$ & $p$-value \\
\hline Age median(IQR) & $38(32-46)$ & $38(32-44)$ & $38(32-47)$ & 0.534 \\
\hline Female & $142(50)$ & $72(49.6)$ & $70(50.4)$ & 0.893 \\
\hline On CART & 140(49.3) & $62(47.3)$ & $78(56.1)$ & 0.138 \\
\hline Duration of cART (months) Median(IQR) & $21(1-58)$ & $10(1-48)$ & $32(9-58)$ & 0.076 \\
\hline Alive at Week-8 Follow-up & $191(70.7)$ & $90(62.1)$ & $101(72.7)$ & 0.057 \\
\hline Duration of Hospital Stay (Days) Median(IQR) & $5(3-8)$ & $4(3-7)$ & $5(4-10)$ & $<0.001$ \\
\hline CD4 T-lymphocytes count (cells/ $\mu \mathrm{L}$ ) median(IQR) & $54(18-144)$ & $41(14-110)$ & $86(25-220)$ & $<0.001$ \\
\hline BMI Median(IQR) & 19.2(17.0-21.5) & 19.1(16.6-20.8) & 19.2(17.3-21.8) & 0.222 \\
\hline $\mathrm{BMI} \leq 18.5$ & $95(33.4)$ & $48(33.1)$ & 47(33.8) & 0.901 \\
\hline On efavirenz based regimen & 109(38.3) & $48(33.1)$ & $61(43.9)$ & 0.061 \\
\hline Haemoglobin g/dl mean(SD) & $9.2(2.8)$ & $8.6(2.4)$ & $9.6(3.0)$ & 0.030 \\
\hline
\end{tabular}

Key: $n=$ number of participants in category, IQR interquartile range, SD standard deviation, BMI Body Mass Index, $C A R T$ combination Antiretroviral therapy, All values are stated as $\mathrm{n}(\%)$ unless indicated otherwise. $p$-values of $\leq 0.05$ were considered statistically significant

regression analysis, dichotomies of optimal/suboptimal and deficient/not deficient serum vitamin $\mathrm{D}$ status were evaluated but only results for suboptimal/optimal category are presented in Table 3.

Female patients had significantly higher median serum 25(OH) D concentration; $23.3 \mathrm{ng} / \mathrm{ml}(\mathrm{IQR} 17.9-32.4) \mathrm{com}-$ pared to males; $20.65 \mathrm{ng} / \mathrm{ml}$ (IQR15.0-30.3) $(p=0.013)$. Age $>50$ years, $\mathrm{CD} 4<200 / \mu \mathrm{L}, \mathrm{BMI} \leq 18.5$, being cARTnaive and being on non-EFV based- regimen were associated with marginally higher median serum $25(\mathrm{OH}) \mathrm{D}$ concentrations though none of these achieved statistical significance. None of these variables was associated with higher odds of vitamin D insufficiency or deficiency in univariate or multivariate logistic regression analysis (Table 3). Further univariate and multivariate logistic regression was also conducted using the same predictor variables but only for the $\mathrm{HIV}^{+} / \mathrm{PTB}^{+}$patients. Still none of these variables were a significant predictor of vitamin $\mathrm{D}$ status.

\section{Median 25(OH) D concentrations and PTB-related outcomes}

Effect of VD status as a dichotomy of optimal or suboptimal on PTB status, duration of hospital stay, cause of death and survival at 8 weeks follow-up post enrolment, was determined using univariate logistic regression. A multivariate logistic regression model incorporating each of PTB status, duration of hospital stay, cause of death and survival at 8 weeks follow-up post enrolment in turn as dependent variables and VD status $(\geq 30$ or $<30 \mathrm{ng} / \mathrm{ml})$, gender, age ( $\geq 50$ or $<50$ years), CD4 cell count $(\geq 200$ or $<200$ cells $/ \mu \mathrm{L}$ ) and cART status (experienced or naïve) as the explanatory variables was fitted. The OR (95\% CI) derived from logistic regression analyses of vitamin D status as an explanatory variable for each of the given PTB-related outcomes adjusted for the other explanatory variables are presented in Table 4 .

In univariate analysis, patients with optimum serum 25(OH) D concentrations were 1.9 times (OR 1.91; 95\% CI 1.1-3.2) more likely to be $\mathrm{PTB}^{+}$compared to those with serum $25(\mathrm{OH})$ D concentrations $<30 \mathrm{ng} / \mathrm{ml}$. The OR decreased to 1.82 (95\% CI 1.1-2.9) when a serum $25(\mathrm{OH}) \mathrm{D}$ concentration cut-off of $20 \mathrm{ng} / \mathrm{ml}$ was used.

During follow-up, 75 (28.3\%) patients died whilst 19 (6.7\%) had incomplete data of whom $4(1.4 \%)$ were lost to follow up. Those with incomplete mortality data had median serum 25(OH) D of $25.9 \mathrm{ng} / \mathrm{ml}$ (IQR18.9-32.4). Of the 75 deceased patients, $49(65.3 \%)$ died from a PTBrelated cause. Median serum 25(OH) D concentration of

Table 2 Median 25(OH) D concentrations and vitamin D status

\begin{tabular}{|c|c|c|c|c|}
\hline Variable & $\begin{array}{l}\text { All } \\
n=284\end{array}$ & $\begin{array}{l}\mathrm{HIV}^{+} / \mathrm{PTB}^{+} \\
n=145\end{array}$ & $\begin{array}{l}\mathrm{HIV}^{+} / \mathrm{PTB}^{-} \\
n=139\end{array}$ & $p$-value \\
\hline Serum 25(OH) D ng/ml Median (IQR) & $22.1(16.4-31.5)$ & $25.3(18.0-33.7)$ & $20.4(14.6-26.9)$ & 0.0003 \\
\hline Vitamin D Deficient & 116(40.9) & $49(33.8)$ & $67(48.2)$ & 0.014 \\
\hline Vitamin D Insufficient & $88(31)$ & $46(31.7)$ & $42(30.2)$ & 0.790 \\
\hline Optimal Vitamin D & $80(28.2)$ & $50(34.5)$ & $30(21.6)$ & 0.016 \\
\hline Severe vitamin D Deficiency & $5(1.8)$ & $0(0)$ & $5(3.6)$ & 0.021 \\
\hline
\end{tabular}

Key: Vitamin D deficient: 25(OH)D: $<20 \mathrm{ng} / \mathrm{ml}$, Vitamin D insufficient: 25(OH) D: $20-29 \mathrm{ng} / \mathrm{ml}$, Optimal Vitamin D 25(OH) D: $\geq 30 \mathrm{ng} / \mathrm{ml}$, Severe Vitamin D Deficiency: $25(\mathrm{OH}) \mathrm{D}:<10 \mathrm{ng} / \mathrm{ml}, n$ number of patients in each category. All values expressed as $n(\%)$ unless otherwise stated. $p$-values of $\leq 0.05$ were considered statistically significant 


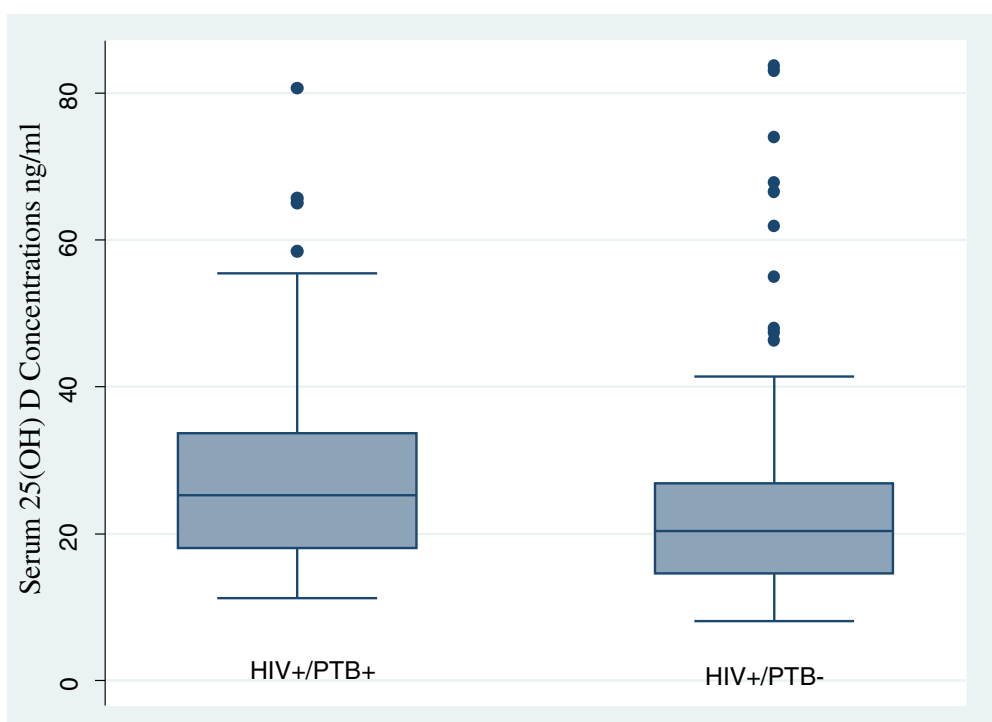

Fig. 1 Box and whisker plot showing the distribution of serum vitamin D concentrations by PTB status. Median serum 25(OH) D concentrations were significantly higher in $\mathrm{HIV}^{+} / \mathrm{PTB}^{+}$group compared to $\mathrm{HIV}^{+} / \mathrm{PTB}^{-}$group $(p=0.0003)$. Key: HIV+ = Human Immunodeficiency Virus positive, PTB $+=$ Pulmonary Tuberculosis positive, PTB- = Pulmonary Tuberculosis negative

patients who died from a PTB-related cause were higher but not significantly so compared to that of those who died from other causes $(p=0.059)$. Similarly, in univariate analysis patients that died from a PTB-related cause were 3.2 times more likely to have serum $25(\mathrm{OH}) \mathrm{D}$ levels $\geq 30 \mathrm{ng} / \mathrm{ml}$ compared to those that died from nonPTB related causes, but the difference was not statistically significant (OR3.19; 95\% CI 0.9-10.7). None of the explanatory variables (VD status, gender, age, CD4 cell count or cART status) for the cause of death were

Table 3 Correlates of serum 25(OH) D levels

\begin{tabular}{|c|c|c|c|c|}
\hline Variable & Serum 25(OH) D ng/ml Median(IQR) & $p$-value & Univariate Odds ratio $(95 \% \mathrm{Cl})$ & $\begin{array}{l}\text { Multivariate Odds ratio } \\
(95 \% \mathrm{Cl})\end{array}$ \\
\hline Gender & & & & $0.91(0.49-1.62)$ \\
\hline Male & $20.65(15.0-30.3)$ & 0.013 & Referent & \\
\hline Female & $23.3(17.9-32.4)$ & & $0.84(0.49-1.42)$ & \\
\hline Age & & & & $1.32(0.40-2.09)$ \\
\hline$\leq 50$ years & $18.91(15.6-27.5)$ & 0.142 & Referent & \\
\hline$>50$ years & $22.63(16.6-32.9)$ & & $1.42(0.7-2.9)$ & \\
\hline CD4 Count & & & & $0.36(0.11-1.17)$ \\
\hline$<200 / \mu \mathrm{L}$ & $22.65(16.6-32.9)$ & 0.127 & $0.69(0.4-1.3)$ & \\
\hline$\geq 200$ & $19.98(15.6-28.8)$ & & Referent & \\
\hline BMI & & & & $0.61(0.27-1.38)$ \\
\hline$\leq 18.5$ & $22.27(16.6-33.6)$ & 0.643 & $0.84(0.5-1.5)$ & \\
\hline$>18.5$ & $21.98(16.4-30.9)$ & & Referent & \\
\hline EFV-Based Regimen & & & & $0.87(0.32-2.34)$ \\
\hline Yes & $20.50(15.1-33.1)$ & 0.664 & Referent & \\
\hline No & $21.81(16.6-30.9)$ & & $0.97(0.4-2.3)$ & \\
\hline CART status & & & & $0.90(0.49-1.62)$ \\
\hline Yes & $20.84(15.6-33.0)$ & 0.244 & Referent & \\
\hline No & $22.97(16.9-30.6)$ & & $1.04(0.6-1.8)$ & \\
\hline
\end{tabular}

Key: IQR interquartile range, $C I$ confidence interval, BMI Body Mass Index, EFV efavirenz, CART combination antiretroviral therapy. $p$-values of $\leq 0.05$ were considered statistically significant 
Table 4 Association of serum 25(OH) D concentrations and outcomes in HIV-infected TB suspects

\begin{tabular}{|c|c|c|c|c|}
\hline Variable & Serum 25(OH) D ng/ml Median(IQR) & $p$-value & $\begin{array}{l}\text { Univariate Odds ratio } \\
(95 \% \mathrm{Cl})\end{array}$ & $\begin{array}{l}\text { Multivariate Odds ratio } \\
(95 \% \mathrm{Cl})\end{array}$ \\
\hline PTB status $n=284$ & & & & $1.84(1.1-3.2)$ \\
\hline 1. $\mathrm{PTB}^{+} n=145$ & $25.3(18.0-33.7)$ & 0.0003 & $1.91(1.1-3.2)$ & \\
\hline 2. $\mathrm{PTB}^{-} n=139$ & $20.4(14.6-26.9)$ & & Referent & \\
\hline 8-week outcome $n=265^{a}$ & & & & $0.90(0.5-1.7)$ \\
\hline 1. Alive $n=190$ & $21.91(16.9-31.1)$ & 0.767 & Referent & \\
\hline 2. Deceased $n=75$ & $21.97(15.8-31.7)$ & & $0.93(0.5-1.7)$ & \\
\hline Cause of Death $n=75$ & & & & $4.25(1.1-16.2)$ \\
\hline 1. PTB $n=49$ & $23.28(16.6-34.8)$ & 0.059 & $3.19(0.9-10.7)$ & \\
\hline 2. Other & $18.47(15.0-29.4)$ & & Referent & \\
\hline Hospital Stay $n=245^{\mathrm{a}}$ & & & & $0.87(0.5-1.6)$ \\
\hline 1. $\leq 7$ days $n=179$ & $22.14(17.0-30.7)$ & 0.740 & Referent & \\
\hline 2. $>7$ days & $22.10(14.5-35.7)$ & & $0.89(0.5-1.7)$ & \\
\hline
\end{tabular}

Key: IQR interquartile range, $C l$ confidence interval, PTB pulmonary tuberculosis, $T B$ tuberculosis. $p$-values of $\leq 0.05$ were considered statistically significant. ${ }^{a}$ some lost to follow up or incomplete data in records and ${ }^{\mathrm{b}} \mathrm{OR}$ adjusted for binaries of gender, age ( $\geq 50$ or $<50$ years), CD4 cell count $(\geq 200$ or $<200$ cells/ $\mu \mathrm{L}$ ) and cART status (experienced or naïve)

statistically significant in univariate logistic regression. However in multivariate analysis, patients that died from a PTB-related cause were 4.3 times more likely to have serum $25(\mathrm{OH})$ D concentration above $\geq 30 \mathrm{ng} / \mathrm{ml}$; OR 4 . 25 (95\% CI1.1-16.2). Stepwise logistic regression analysis for predictors of cause of PTB related death, fitted a model with gender (OR 0.5; 95\%CI 0.2-1.4), cART status (OR 0.39; 95\%CI 0.1-1.1) and VD status (OR 3.89; 95\% CI 1.1-13.8).

The patients that were recorded as deceased $(n=75)$ at the 8-week follow up time point were re-stratified by initial laboratory based PTB diagnosis. A statistically significantly higher median serum $25(\mathrm{OH})$ D concentration 24. $92 \mathrm{ng} / \mathrm{ml}$ (IQR 16.7-34.8) was observed in the $\mathrm{PTB}^{+}$ group $(n=38)$ compared to the $\mathrm{PTB}^{-}$group $(n=37)$ with $25(\mathrm{OH}) \mathrm{D}$ of $17.58 \mathrm{ng} / \mathrm{ml}$ (IQR 14.6-27.1); $p=0.026$.

No significant differences were observed in median serum $25(\mathrm{OH})$ D concentrations between patients that died and those that were alive $(p=0.77)$ or those hospitalised for $\geq 7$ days and those hospitalised for shorter durations $(p=0.74)$ after the 8 weeks follow up period.

\section{Discussion}

Our results contribute to a small but growing pool of studies that refute the commonly accepted hypothesis that lower serum $25(\mathrm{OH}) \mathrm{D}$ concentrations are associated with PTB $[10,15,16,19,22]$. In the present study, median serum $25(\mathrm{OH})$ D concentrations for both the $\mathrm{HIV}^{+} / \mathrm{PTB}^{+}$and $\mathrm{HIV}^{+} / \mathrm{PTB}^{-}$groups were above the threshold for VDD but still below the cut-off for optimum serum $25(\mathrm{OH})$ D concentration. In addition, we observed significantly higher proportion of patients with optimum $25(\mathrm{OH}) \mathrm{D}$ concentrations in the $\mathrm{HIV}^{+}$/
$\mathrm{PTB}^{+}$group and significantly higher proportion of VDD patients in the $\mathrm{HIV}^{+} / \mathrm{PTB}^{-}$group.

Furthermore, patients with serum $25(\mathrm{OH}) \mathrm{D}$ concentrations above the optimum threshold were twice more likely to be $\mathrm{PTB}^{+}$compared to those with lower concentrations. Surprisingly, we observed no significant association between vitamin D status and all-cause mortality although in multivariate logistic regression analysis patients that died from a PTB-related cause were 4.3 times more likely to have serum $25(\mathrm{OH}) \mathrm{D}$ levels $\geq 30 \mathrm{ng} / \mathrm{ml}$ compared to those that died from non-PTB related causes.

Our findings though, are in discordance with the generally implied role of vitamin D in mycobacterial immunity that has been suggested by in vitro studies. In vitro studies suggest a role of $25(\mathrm{OH}) \mathrm{D}$ in control of MTB infection and by deduction, increased susceptibility in individuals with insufficient $25(\mathrm{OH}) \mathrm{D}$ levels. In the present study, $\mathrm{HIV}^{+} / \mathrm{PTB}^{+}$patients had insufficient but significantly higher median serum 25(OH) D concentrations compared to $\mathrm{HIV}^{+} / \mathrm{PTB}^{-}$individuals.

Our observation of higher median serum 25(OH) D levels in $\mathrm{HIV}^{+} / \mathrm{PTB}^{+}$participants compared to $\mathrm{HIV}^{+} / \mathrm{PTB}^{-}$ patients whilst unexpected could be a consequence of active PTB and HIV-infection modulation. MTB and HIV-1gp120 peptides stimulate toll-like receptors $1 / 2$ which in turn have been reported to induce CYP27B1 expression in infected macrophages in vitro [7] We speculate that if the same process occurs in vivo, the resultant accelerated production of $1,25(\mathrm{OH}) \mathrm{D}$ might in turn lead to increased mobilisation of $25(\mathrm{OH}) \mathrm{D}$ from adipose tissue and consequent elevation in circulation. Alternatively, HIV induced chronic inflammation characterised by tumour necrosis factor-alpha (TNF- $\alpha$ ) overproduction, may result in renal $1 \alpha$-hydroxylase impairment [23] leading to reduced parathyroid stimulatory effect 
on $1,25(\mathrm{OH}) 2 \mathrm{D}$ production thereby leading to accumulation of $25(\mathrm{OH}) \mathrm{D}$ in circulation.

We were unable to verify the assertion by Zeng et al, who in a meta-analysis concluded that only severe VDD $(<10 \mathrm{ng} / \mathrm{ml})$ was associated with significant risk of active TB [11]. Five patients were severely vitamin $\mathrm{D}$ deficient in our study and interestingly all were $\mathrm{PTB}^{-}$lending support to our observation of lack of association of VDD with PTB albeit the number is small.

The overall $40.9 \%$ prevalence of VDD in our study falls within the range of $29-73 \%$ reported in literature [24]. Although only an overall $28.2 \%$ of the patients had optimal serum $25(\mathrm{OH})$ D levels, the majority of these were $\mathrm{HIV}^{+} / \mathrm{PTB}^{+}$. In concordance with findings from a study conducted in Uganda [25], 66.2\% of $\mathrm{HIV}^{+} / \mathrm{PTB}^{+}$ patients had serum $25(\mathrm{OH})$ D levels above $20 \mathrm{ng} / \mathrm{ml}$ but this is sharply contrasted by a study from Cape Town South Africa [26] that reported only $14 \%$ of $\mathrm{HIV}^{+} / \mathrm{PTB}^{+}$ patients with concentrations above $20 \mathrm{ng} / \mathrm{ml}$. Such latitudinal-related differences in relative proportions of individuals with insufficient $25(\mathrm{OH})$ D concentrations among Black Africans from different countries could be attributed to the solar zenith angle that influences the efficiency of ultra violet induced cutaneous synthesis of vitamin D [27].

\section{Correlates of serum vitamin D concentration}

Females had significantly higher median serum $25(\mathrm{OH})$ D concentrations compared to males contrary to reports of association of male gender with higher serum vitamin D concentrations [28]. Other studies reported no significant differences by gender [29]. We speculate that higher median serum $25(\mathrm{OH})$ D concentrations in females might have been associated with wasting, the hallmark of both PTB and HIV [30]. Female patients in the present study had marginally higher BMI compared to males. The higher adiposity associated with lower serum $25(\mathrm{OH}) \mathrm{D}$ concentrations, may however imply more vitamin $\mathrm{D}$ being stored in adipose tissue hence enhanced release during wasting associated with HIV infection and/or active PTB.

Age, CD4+ T-lymphocyte count, BMI, cART status and EFV-based cART regimen were not associated with vitamin D status in univariate or multivariate analysis. Older age has been reported as a risk factor for VDD in an HIV-infected population [31] due to reduced dermal efficiency to synthesize vitamin D [32]. Our findings of no age association may be due to the relatively younger median age of our study patients.

Patients on cART had marginally insignificantly lower median 25(OH) D levels compared to cART-naïve. The association between VDD and cART is controversial. Although VDD has been associated with cART [29] other studies have reported lack of association [8] whilst others reported higher 25(OH) D levels in those on cART [33]. The modulation of vitamin $\mathrm{D}$ status by cART has largely been attributed to the effects of protease inhibitors and certain non-nucleoside reverse transcriptase inhibitors (NNRTIs) on vitamin D metabolism.

Similar to findings from another study [34], patients on an EFV-based cART regimen in the present study had marginally insignificantly lower median $25(\mathrm{OH}) \mathrm{D}$ levels. NNRTIs notably EFV, have been reported to accelerate $25(\mathrm{OH}) \mathrm{D}$ catabolism through the induction of the enzyme CYP24 which converts both $25(\mathrm{OH}) \mathrm{D}$ and the active form of vitamin $\mathrm{D}, 1,25(\mathrm{OH}) \mathrm{D}$, to inactive metabolites [35]. EFV has also been reported to reduce the expression of cytochrome CYP2R1, which hydroxylates vitamin D3 and vitamin D2, an initial step in vitamin D activation [36]. Although the relatively shorter median duration since cART initiation in our study may plausibly contribute to the differences, the possibility of racial differences in the response to EFV cannot be ruled out. Indeed, lack of response to EFV has been reported for non-Caucasian patients [37]. We however, note the possible contribution of diminished power to detect any difference given the limited number of participants on cART and also those on an EFV-based regimen.

\section{8-week mortality and $25(\mathrm{OH}) \mathrm{D}$ concentrations}

Hypovitaminosis D has been associated with poorer disease outcomes and higher risk of all-cause mortality in the general population as well as in both cART-experienced and naive HIV-infected individuals $[8,31,38]$. In the present study, median $25(\mathrm{OH}) \mathrm{D}$ concentrations were not significantly different between patients that died within the 8-week follow up period and those that were still alive. In multivariate logistic regression analysis, patients that died from a PTB-related cause within 8 weeks had significantly higher odds of having optimal vitamin D status compared to those that were alive. This observation is concordant with the other findings reported in this study and could be explained in a similar manner.

We observed no significant difference in median $25(\mathrm{OH}) \mathrm{D}$ concentrations between patients admitted into hospital for at least 7 days and those that were admitted for longer. In concordance with current findings, Sherwood et al. reported no significant associations between $25(\mathrm{OH}) \mathrm{D}$ levels with mortality or length of hospitalisation [39]. Similarly, a study conducted in Tanzania observed no relationship between all-cause mortality and dichotomous outcomes of insufficient versus sufficient serum $25(\mathrm{OH}) \mathrm{D}$ concentrations although those with sufficient levels had a lower risk of death [11].

\section{Limitations}

The limitations of our study include (i) the cross sectional study design which precludes inference of causal 
relationships between serum 25(OH) D and PTB, (ii) possibility of reverse causation as $25(\mathrm{OH}) \mathrm{D}$ levels were measured when patients were already HIV and/or MTB infected, thus the temporal relationship between infection and vitamin D status could therefore not be established, (iii) stratification of patients into such substrata as cART regimen and cause of death could have diminished statistical power to detect any effect modification and (iv)the lack of consensus on the definitions of vitamin D status in literature also compromised the interpretation of findings across different studies.

Despite these limitations, our study has some strengths. The study sample size was relatively large and although unmatched for gender, age, proportion on cART, BMI and duration on CART, there were no significant differences between the two groups thus giving credence to our findings.

\section{Conclusions}

Our findings though at variance with the generally accepted association between serum vitamin D status and PTB, are in concordance with findings from a few other studies that report an association between high serum $25(\mathrm{OH}) \mathrm{D}$ concentrations and risk of PTB. It is possible that the reason for this observed variation could be genetic given the complex and diverse actions of vitamin D. Thus, genetic polymorphisms in the vitamin D receptor, or in the multiple enzymes involved in vitamin D metabolism, remain attractive candidates for further study.

\section{Abbreviations \\ 25(OH) D: 25 Hydroxyvitamin D; BMI: Body Mass Index; CART: Combination anti-retroviral therapy; CD4: Cluster of differentiation 4; Cl: Confidence interval; EFV: Efavirenz; HIV: Human immunodeficiency virus; IQR: Interquartile range; LAM: Lipoarabinomannan; MRCZ: Medical research council of Zimbabwe; MTB: Mycobacterial tuberculosis; NNRTIs: Non-nucleoside reverse transcriptase inhibitors; OR: Odds ratio; PTB: Pulmonary tuberculosis; RCT: Randomised controlled trial; TB: Tuberculosis; VDD: Vitamin D deficiency; Xpert MTB RIF: GeneXpert Mycobacteria tuberculosis rifampicin}

\section{Acknowledgements}

We thank the study participants from the RCT-LAM study for their participation in the parent study and for giving us permission to use their left-over archived specimens and data in the current study.

\section{Funding}

The authors gratefully acknowledge funding from the European and Developing Countries Trials Partnership (IP.0932040009), Southern Africa Consortium for Research Excellence and grant number 2U2RTW007367 from the Fogarty International Centre, National Institutes of Health, USA through the International Clinical, Operations, and Health Services Research Training Award for AIDS and TB. The funders played no role in the design of the study and collection, analysis, and interpretation of data and in writing the manuscript.

\section{Availability of data and materials}

The datasets used and/or analysed during the current study are available from the corresponding author on reasonable request.

\section{Authors' contributions}

CM, LSZ, WBM and MWM conceived the study and its design. CM, MMC and DZM participated in the collection of clinical material and study participant recruitment. CM, DZM and KM conducted the laboratory tests. TB and CM performed data analysis. CM wrote the first draft with input from LSZ, WBM, MWM, DZM, KM, TB and MMC. All authors reviewed and approved the final version of the manuscript.

Ethics approval and consent to participate

The study protocol was approved by the Medical Research Council of Zimbabwe (MRCZ/A/1906). All the patients in the parent study (RCT-LAM) consented to future use of their left-over archived specimens and data in future TB- and/or HIV-related studies.

\section{Competing interests}

The authors declare that they have no competing interests.

\section{Publisher's Note}

Springer Nature remains neutral with regard to jurisdictional claims in published maps and institutional affiliations.

\section{Author details}

${ }^{1}$ Department of Chemical Pathology, University of Zimbabwe, College of Health Sciences, P.O. Box A178, Avondale, Harare, Zimbabwe. ${ }^{2}$ Department of Immunology, University of Zimbabwe, College of Health Sciences, P.O. Box A178, Avondale, Harare, Zimbabwe. ${ }^{3}$ Biomedical Research and Training Institute, Harare, Zimbabwe. ${ }^{4}$ Department of Obstetrics and Gynaecology, University of Zimbabwe, College of Health Sciences, P.O. Box A178, Avondale, Harare, Zimbabwe.

Received: 1 January 2018 Accepted: 2 May 2018

Published online: 08 May 2018

\section{References}

1. World Health Organization. Global tuberculosis report 2015. Geneva: World Health Organization; 2015. http://apps.who.int/iris/bitstream/10665/191102/ 9789241565059_eng.pdf. Accessed 29 Sept 2017

2. Adeiza MA, Abba AA, Okpapi JU. HIV-associated tuberculosis: a sub-saharan african perspective. Sub-Saharan Afr J Med. 2014;1:1.

3. Campbell GR, Spector SA. Vitamin D inhibits human immunodeficiency virus type 1 and Mycobacterium tuberculosis infection in macrophages through the induction of autophagy. PLoS Pathog. 2012; https://doi.org/10.1371/ journal.ppat.1002689.

4. Kamen DL, Tangpricha V. Vitamin D and molecular actions on the immune system: modulation of innate and autoimmunity. J Mol Med. 2010:88:441-50.

5. Holick MF. Deficiency of sunlight and vitamin D. BMJ. 2008;336:1318-9.

6. Lambert AA, Drummond MB, Mehta SH, Brown TT, Lucas GM, Kirk GD, et al. Risk factors for vitamin D deficiency among HIV-infected and uninfected injection drug users. PloS one. 2014; https://doi.org/10.1371/journal.pone.0095802.

7. Coussens AK, Martineau AR, Wilkinson RJ. Anti-inflammatory and antimicrobial actions of vitamin D in combating TB/HIV. Scientifica. 2014; https://doi.org/10.1155/2014/903680.

8. Shepherd L, Souberbielle JC, Bastard JP, Fellahi S, Capeau J, Reekie J, et al. Prognostic value of vitamin D level for all-cause mortality, and association with inflammatory markers, in HIV-infected persons. J Infect Dis. 2014;210: 234-43.

9. Mehta S, Giovannucci E, Mugusi FM, Spiegelman D, Aboud S, Hertzmark E, et al. Vitamin D status of HIV-infected women and its association with HIV disease progression, anemia, and mortality. PloS one. 2010; https://doi.org/ 10.1371/journal.pone.0008770.

10. Owolabi O, Agbla S, Owiafe P, Donkor S, Togun T, Sillah AK, et al. Elevated serum 25-hydroxy $(\mathrm{OH})$ vitamin $D$ levels are associated with risk of TB progression in Gambian adults. Tuberculosis. 2016:98:86-91.

11. Zeng J, Wu G, Yang W, Gu X, Liang W, Yao Y, et al. A serum vitamin D level $<25 \mathrm{nmol} / /$ pose high tuberculosis risk: a meta-analysis. PloS one. 2015; https://doi.org/10.1371/journal.pone.0126014.

12. Huang SJ, Wang XH, Liu ZD, Cao WL, Han Y, Ma AG, et al. Vitamin D deficiency and the risk of tuberculosis: a meta-analysis. Drug Des Devel Ther. 2017;11:91-102.

13. Daley $P$, Jagannathan $V$, John $K R$, Sarojini J, Latha A, Vieth $R$, et al. Adjunctive vitamin $D$ for treatment of active tuberculosis in India: a randomised, doubleblind, placebo-controlled trial. Lancet Infect Dis. 2015;15:528-34.

14. Tukvadze N, Sanikidze E, Kipiani M, Hebbar G, Easley KA, Shenvi N, et al. High-dose vitamin D3 in adults with pulmonary tuberculosis: a double-blind randomized controlled trial. Am J Clin Nutr. 2015;102:1059-69. 
15. Friis H, Range N, Changalucha J, PrayGod G, Jeremiah K, Faurholt-Jepsen D, et al. Vitamin D status among pulmonary TB patients and non-TB controls: a cross-sectional study from Mwanza, Tanzania. PloS one. 2013; https://doi. org/10.1371/journal.pone.0081142.

16. Nielsen NO, Skifte T, Andersson M, Wohlfahrt J, Søborg B, Koch A, et al. Both high and low serum vitamin D concentrations are associated with tuberculosis: a case-control study in Greenland. Br J Nutr. 2010;104:1487-91.

17. Peter JG, Zijenah LS, Chanda D, Clowes P, Lesosky M, Gina P, et al. Effect on mortality of point-of-care, urine-based lipoarabinomannan testing to guide tuberculosis treatment initiation in HIV-positive hospital inpatients: a pragmatic, parallel-group, multicountry, open-label, randomised controlled trial. Lancet. 2016;387:1187-97.

18. Zijenah LS, Kadzirange G, Bandason T, Chipiti MM, Gwambiwa B, Makoga F, et al. Comparative performance characteristics of the urine lipoarabinomannan strip test and sputum smear microscopy in hospitalized HIV-infected patients with suspected tuberculosis in Harare Zimbabwe. BMC Infect Dis. 2016;16:20.

19. Conesa-Botella A, Goovaerts O, Massinga-Loembe M, Worodria W, Mazakpwe D, Luzinda K, et al. Low prevalence of vitamin D deficiency in Ugandan HIV-infected patients with and without tuberculosis. Int J Tuberc Lung Dis. 2012;16:1517-21.

20. Dawson-Hughes B, Heaney RP, Holick MF, Lips P, Meunier PJ, Vieth R. Estimates of optimal vitamin D status. Osteoporos Int. 2005;16:713-6.

21. Wejse C, Olesen R, Rabna P, Kaestel P, Gustafson P, Aaby P, et al. Serum 25hydroxyvitamin $D$ in a west African population of tuberculosis patients and unmatched healthy controls. Am J Clin Nutr. 2007;86:1376-83.

22. Musarurwa C, Zijenah LS, Duri DZ, Mateveke-Dangaiso K, Mhandire K, Chipiti $M M$, et al. Association of high serum vitamin $D$ concentrations with active pulmonary TB in an HIV co-endemic setting, Harare Zimbabwe. BMC Infect Dis. 2017;17:142

23. Mansueto P, Seidita A, Vitale G, Gangemi S, laria C, Cascio A. Vitamin D Deficiency in HIV Infection: Not Only a Bone Disorder. BioMed Res Int. 2015; https://doi.org/10.1155/2015/735615.

24. Dao CN, Patel P, Overton ET, Rhame F, Pals SL, Johnson C, et al. Low vitamin D among HIV-infected adults: prevalence of and risk factors for low vitamin D levels in a cohort of HIV-infected adults and comparison to prevalence among adults in the US general population. Clin Infect Dis. 2011;52:396-405.

25. Nansera D, Graziano FM, Friedman DJ, Bobbs MK, Jones AN, Hansen KE. Vitamin $D$ and calcium levels in Ugandan adults with human immunodeficiency virus and tuberculosis. Int J Tuberc Lung Dis. 2011;15:1522.

26. Martineau AR, Timms PM, Bothamley GH, Hanifa Y, Islam K, Claxton AP, et al. High-dose vitamin D3 during intensive-phase antimicrobial treatment of pulmonary tuberculosis: a double-blind randomised controlled trial. Lancet. 2011;377:242-50.

27. Engelsen $\mathrm{O}$. The relationship between ultraviolet radiation exposure and vitamin D status. Nutrients. 2010;2:482-95.

28. Al-Horani H, Abu Dayyih W, Mallah E, Hamad M, Mima, M, Awad R, et al. Nationality, Gender, Age, and Body Mass Index Influences on Vitamin D Concentration among Elderly Patients and Young Iraqi and Jordanian in Jordan. Biochem Res Int. 2016; https://doi.org/10.1155/2016/8920503.

29. Conesa-Botella A, Florence E, Lynen L, Colebunders R, Menten J, MorenoReyes R. Decrease of vitamin D concentration in patients with HIV infection on a non nucleoside reverse transcriptase inhibitor-containing regimen. AIDS Res Ther. 2010;7:40.

30. Wanke C, Kotler D. HIV wasting collaborative consensus committee. Collaborative recommendations: the approach to diagnosis and treatment of HIV wasting. J Acquir Immune Defic Syndr. 2004;37suppl:S284-8.

31. Viard JP, Souberbielle JC, Kirk O, Reekie J, Knysz B, Losso M, et al. Vitamin D and clinical disease progression in HIV infection: results from the EuroSIDA study. AIDS. 2011;25:1305-15.

32. Pilz S, Dobnig H, Nijpels G, Heine RJ, Stehouwer CD, Snijder MB, et al. Vitamin D and mortality in older men and women. Clin Endocrinol. 2009;71: 666-72.

33. Ramayo E, Gonzalez-Moreno MP, Macias J, Cruz-Ruíz M, Mira JA, Villar-Rueda AM, et al. Relationship between osteopenia, free testosterone, and vitamin D metabolite levels in HIV-infected patients with and without highly active antiretroviral therapy. AIDS Res Hum Retrovir. 2005;21:915-21.

34. Poowuttikul P, Thomas R, Hart B, Secord E. Vitamin D insufficiency/ deficiency in HIV-infected inner city youth. J Int Assoc Provid AIDS Care. 2014;13:438-42.
35. Schwartz JB, Moore KL, Yin M, Sharma A, Merenstein D, Islam T, et al. Relationship of vitamin D, HIV, HIV treatment, and lipid levels in the Women's interagency HIV study of HIV-infected and uninfected women in the United States. J Int Assoc Provid AIDS Care. 2014;13:250-9.

36. Cheng JB, Levine MA, Bell NH, Mangelsdorf DJ, Russell DW. Genetic evidence that the human CYP2R1 enzyme is a key vitamin D 25hydroxylase. Proc Natl Acad Sci U S A. 2004;101:7711-5.

37. Havers F, Smeaton L, Gupte N, Detrick B, Bollinger RC, Hakim J, et al. 25Hydroxyvitamin D insufficiency and deficiency is associated with HIV disease progression and virological failure post-antiretroviral therapy initiation in diverse multinational settings. J Infect Dis. 2014;210:244-53.

38. Sudfeld CR, Wang M, Aboud S, Giovannucci EL, Mugusi FM, Fawzi WW. Vitamin $\mathrm{D}$ and HIV progression among Tanzanian adults initiating antiretroviral therapy. PloS one. 2012; https://doi.org/10.1371/journal.pone.0040036.

39. Sherwood JE, Mesner OC, Weintrob AC, Hadigan CM, Wilkins KJ, CrumCianflone NF, et al. Vitamin D deficiency and its association with low bone mineral density, HIV-related factors, hospitalization, and death in a predominantly black HIV-infected cohort. Clin Infect Dis. 2012;55:1727-36.

\section{Ready to submit your research? Choose BMC and benefit from:}

- fast, convenient online submission

- thorough peer review by experienced researchers in your field

- rapid publication on acceptance

- support for research data, including large and complex data types

- gold Open Access which fosters wider collaboration and increased citations

- maximum visibility for your research: over $100 \mathrm{M}$ website views per year

At BMC, research is always in progress.

Learn more biomedcentral.com/submissions 